\title{
Polymethine Dyes as Probes for Detecting the SARS-COV-2 Coronavirus: In Silico Molecular Docking Study
}

\author{
P. G. Pronkin ${ }^{a,}$ * and A. S. Tatikolov ${ }^{a}$ \\ ${ }^{a}$ Emanuel Institute of Biochemical Physics, Russian Academy of Sciences, Moscow, 119991 Russia \\ *e-mail: pronkinp@gmail.com
}

Received July 2, 2020; revised July 2, 2020; accepted September 21, 2020

\begin{abstract}
The noncovalent interaction between various polymethine dyes (45 compounds in total) and a spike protein (S), one of the main structural component of the SARS-CoV-2 coronavirus, is studied in silico (molecular docking) to develop effective probes to detect the virus. The interaction energies and the spatial configurations of the complexes of the dye molecules with $\mathrm{S}$ are found. We showed that cationic polymethine dyes and neutral squarylium dyes do not form stable complexes with S. Some anionic dyes having negative total energies $E_{\text {tot }}$ may be recommended for practical research.
\end{abstract}

Keywords: SARS-CoV-2 coronavirus, spike protein, polymethine dyes, non-covalent interaction, molecular docking

DOI: $10.1134 / \mathrm{S} 1990793121010267$

\section{INTRODUCTION}

The pandemic of the new coronavirus SARS-CoV-2, which began in 2019 and remains present today, has posed a global challenge to find approaches to diagnose the coronavirus infection and treat sick patients. From this point of view, it is important to develop effective rapid analysis methods for the coronavirus infection. One of these methods is the spectral-fluorescent probe method, in which polymethine (cyanine and squarylium) dyes may be used as probes. They possess high extinction coefficients, absorption, and emission in the long-wavelength region, covering the optical transparency window of biological samples and tissues; in addition, their photophysical and photochemical properties depend on the molecular environment [1]. Cyanine and squarylium dyes can interact with biomolecules to form noncovalent complexes to increase the fluorescence, so that they may be used as probes in systems containing biomolecules [2, 3]. The dyes (including cyanine) are considered as spectral-fluorescent probes to study various viruses [4]. In particular, the association of some cyanine dyes with the bacteriophage MS2 was studied for its detection and characterization; moreover, together with other methods, molecular docking was used [5]. The development of probes to detect coronavirus should include the study of noncovalent interactions between dyes and its molecular components. Various structures and properties of polymethine dyes, which have a different length of the polymethine chain, terminal heterocycles, and substituents in the chain and in heterocycles, required the use of in silico simulation to select the effective candidate compounds for further studies of their interaction with the virus in vitro. Molecular docking is widely used to study the interaction between various therapeutic agents and the protein components of SARS-CoV-2, which provides valuable information on the interaction energy (or affinity) of a substrate molecule with the selected protein components and the binding sites of a substrate with these proteins [6-8].

The noncovalent interaction of various polymethine and squarylium dyes (45 compounds in total) with one of the most important structural components of the SARS-CoV-2 coronavirus, the spike protein (S), which forms spikes on the surface of a viral particle, is studied in this work. Both cationic and anionic dyes are considered to reveal the influence of the charge on this interaction.

\section{EXPERIMENTAL}

The molecular docking experiments were performed using the DockThor website $[9,10]$ via a web interface. The structure of the target protein $\mathrm{S}$ was taken from DockThor. It is also available on the Protein Data Bank (PDB) website (ID 7BZ5) [11].

The hydrogen atoms were added, the hydrogen bonds were optimized ( $\mathrm{pH} 7$ ), the antibodies and nonprotein molecules were removed, and the selenomethionine $(\mathrm{Se}-\mathrm{Met})$ residues in the structure were replaced by the methionine residues (Met) (DockThor) in the PDB file of the spike protein structure. The proposed structure of the target protein was used 
as is without the additional adjustment of the protonation of the amino acid residues. The experiments were carried out in the blind docking mode: the approximation lattice size was $40 \AA$, the center was $x=$ $-30.68, y=30.43$, and $z=22.38$, with a sampling step of $0.42 \AA$. The six best configurations were taken into account to analyze the results.

An Avogadro molecular editor [12, 13] was used to obtain the PDB structures of ligand dyes and to optimize their geometry (MMFF94 force field). The UCSF Chimera package $[14,15]$ was used for the 3D visualization and analysis of the docking results.

Symmetrical monomethine, trimethine, pentamethine, and heptamethine cyanines (cationic and anionic) with various heterocycles (benzimidazolyl, benzthiazolyl, and benzoxazolyl) and substituents in heterocycles were studied. The trimethine cyanines (carbocyanines) also had various substituents in the meso-position of the polymethine chain $\left(\mathrm{CH}_{3}, \mathrm{C}_{2} \mathrm{H}_{5}\right.$, $\mathrm{CH}_{3} \mathrm{O}, \mathrm{CH}_{3} \mathrm{~S}$, and $\mathrm{Cl}$ ), because the meso-substituted thiacarbocyanines were previously found to be effective probes for biomacromolecules [16]. Figure 1 shows the structures of the cyanine dyes. The squarylium dyes, including squarylium indocyanines and thiacyanines, which have anionic sulfonate groups (Fig. 2), were also studied.

Trans-isomers of dyes were taken as the initial conformations in the cases of mono-, penta-, and heptamethine cyanines [17]. The stability of possible dyeprotein complexes was assessed from the sign and the value of the total energy $E_{\text {tot }}$ of the system obtained after docking: the stable complexes are formed at sufficiently low negative energies (i.e., high in absolute value).

\section{RESULTS \\ Docking of Cationic Cyanine Dyes}

The interaction between the $\mathrm{S}$ and ten cationic thia-trimethine cyanine and oxa-trimethine cyanine dyes bearing the substituents in the meso-position of a polymethine chain and terminal heterocycles (structures D1-D10, Fig. 1) was studied. The initial structures of the meso-substituted trimethine cyanine dyes corresponded to their cis-configuration as the most stable in an aqueous solution [18]. The study showed that noncovalent interaction with a protein changes the isomeric configuration of the dye molecules. In particular, the distorted trans-configurations are typical of thiacarbocyanines D1-D4, and the strongly twisted cis-form is characteristic of oxacarbocyanines D8. The dye molecules are located at a distance of 7 to $10 \AA$ from the Leu184, Glu183, Phe131, and Phe96 residues.

All dyes have positive total energies $E_{\text {tot }}(31.24 \pm$ $\left.6.0 \mathrm{kcal} \mathrm{mol}^{-1}\right)$; the lowest $E_{\text {tot }}$ value was observed for oxacarbocyanine D8 $\left(22.85 \pm 1.07 \mathrm{kcal} \mathrm{mol}^{-1}\right)$. The high positive $E_{\text {tot }}$ values indicate that the cationic poly- methine dye complexes with $\mathrm{S}$ are presumably unstable. As a result, we mainly studied the anionic polymethine dyes.

\section{Docking of Anionic Cyanine Dyes}

Monomethine cyanines. The S-protein and the series of six anionic monomethine cyanines bearing benzoxazole and benzothiazole terminal heterocycles and various substituents in the heterocyclic residues (Fig. 1, structures 1.1-1.6) were studied with docking. The dye molecules are negatively charged due to two sulfopropyl groups in the 3 and 3' positions. For most of the dyes (except 1.4) have negative $E_{\text {tot }}$ values were obtained (Table 1), which indicates that these dyes are able to form stable complexes with $\mathrm{S}$. The monomethine cyanine dyes are located at a distance of 6 to $8 \AA$ from the As95, Phe131, and Leu185 residues; the configurations of thiacyanine dyes correspond to the twisted trans-isomers; and those of oxacyanines, to more planar trans-configurations. Figure 3a shows the spatial docking of the dye complex 1.5 with S.

Trimethine cyanines. The interaction between $\mathrm{S}$ and 15 meso-substituted anionic thia- and oxatrimethine cyanine (carbocyanine) dyes, whose molecules are negatively charged due to the two sulfo groups, is considered (Fig. 1, structures 2.1-2.15). The starting structures of the dyes corresponded to their cis configuration to be the most stable for mesosubstituted anionic carbocyanines in an aqueous solution [19]. The in silico results indicated that some dyes were able to form energetically stable complexes with S. In particular, the compounds 2.1-2.3, 2.9-2.11, 2.13, and 2.15 have negative total energies $\left(E_{\text {tot }}<0\right.$; Table 1), and oxacarbocyanines $\mathbf{2 . 1 0}$ and $\mathbf{2 . 1 1}$ have the lowest $E_{\text {tot }}$ values. The bulky phenyl substituents and the condensed benzene rings in the terminal heterogroups of the dyes can increase the $E_{\text {tot }}$ to positive values (for dyes 2.4-2.8 and 2.14). The high positive $E_{\text {tot }}$ values indicate that dye complexes 2.4-2.8, 2.12, and $\mathbf{2 . 1 4}$ with $\mathrm{S}$ are unstable. In the $\mathrm{S}$ complexes, the three-dimensional structures of oxacarbocyanine dyes correspond mainly to the twisted cis- and periplanar configurations; the thia-dyes can exist as periplanar structures and distorted (nonplanar) trans-isomers. In the $\mathrm{S}$ complexes, the trimethinecyanines are located at a distance of 5 to $8 \AA$ from Glu 183 and 10 to $12 \AA$ from the Phe 96 and Phe 131 residues. Figure $3 b$ shows the spatial complex of dye 2.1 with S.

Pentamethine cyanines. The molecular docking of six thia- and oxa-pentamethine cyanine dyes (dicarbocyanines 3.1-3.6, Fig. 1) showed that such compounds can potentially form stable complexes with $\mathrm{S}$ (Table 2). The pentamethine cyanines have negative total energies (except dye 3.2), and the lowest $E_{\text {tot }}$ values were obtained for the oxa dyes 3.6 and 3.5 (Table 2) as in the case of trimethine cyanines. 


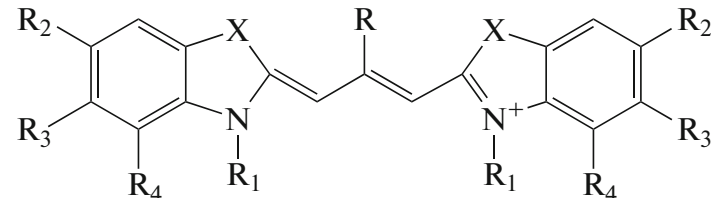

D1 $\mathrm{X}=\mathrm{S}, \mathrm{R}=-\mathrm{CH}_{3}, \mathrm{R}_{1}=-\mathrm{C}_{2} \mathrm{H}_{5}, \mathrm{R}_{2}=\mathrm{R}_{3}=\mathrm{R}_{4}=\mathrm{H}$

D2 $\mathrm{X}=\mathrm{S}, \mathrm{R}=-\mathrm{C}_{2} \mathrm{H}_{5}, \mathrm{R}_{1}=-\mathrm{C}_{2} \mathrm{H}_{5}, \mathrm{R}_{2}=\mathrm{R}_{3}=\mathrm{R}_{4}=\mathrm{H}$

D3 $\mathrm{X}=\mathrm{S}, \mathrm{R}=-\mathrm{OCH}_{3}, \mathrm{R}_{1}=-\mathrm{C}_{2} \mathrm{H}_{5}, \mathrm{R}_{2}=\mathrm{R}_{3}=\mathrm{R}_{4}=\mathrm{H}$

D4 $\mathrm{X}=\mathrm{S}, \mathrm{R}=-\mathrm{SCH}_{3}, \mathrm{R}_{1}=-\mathrm{C}_{2} \mathrm{H}_{5}, \mathrm{R}_{2}=\mathrm{R}_{3}=\mathrm{R}_{4}=\mathrm{H}$

D5 $\mathrm{X}=\mathrm{S}, \mathrm{R}=-\mathrm{Cl}, \mathrm{R}_{1}=-\mathrm{C}_{2} \mathrm{H}_{5}, \mathrm{R}_{2}=\mathrm{R}_{3}=\mathrm{R}_{4}=\mathrm{H}$

D6 $\mathrm{X}=\mathrm{S}, \mathrm{R}=-\mathrm{C}_{2} \mathrm{H}_{5}, \mathrm{R}_{1}=-\mathrm{C}_{2} \mathrm{H}_{5}, \mathrm{R}_{2}=-\mathrm{OCH}_{3}, \mathrm{R}_{3}=\mathrm{R}_{4}=\mathrm{H}$

D7 $\mathrm{X}=\mathrm{S}, \mathrm{R}=\mathrm{R}_{2}=-\mathrm{OCH}_{3}, \mathrm{R}_{1}=-\mathrm{C}_{2} \mathrm{H}_{5}, \mathrm{R}_{3}=\mathrm{R}_{4}=\mathrm{H}$

D8 $\mathrm{X}=\mathrm{O}, \mathrm{R}=-\mathrm{C}_{2} \mathrm{H}_{5}, \mathrm{R}_{1}=-\mathrm{CH}_{3}, \mathrm{R}_{2}=\mathrm{R}_{3}=\mathrm{R}_{4}=\mathrm{H}$

D9 $\mathrm{X}=\mathrm{O}, \mathrm{R}=-\mathrm{C}_{2} \mathrm{H}_{5}, \mathrm{R}_{1}=-\mathrm{C}_{2} \mathrm{H}_{5}, \mathrm{R}_{2}=\mathrm{R}_{4}=\mathrm{H}, \mathrm{R}_{3}=-\mathrm{CH}_{3}$

D10 X $=\mathrm{O}, \mathrm{R}=-\mathrm{C}_{2} \mathrm{H}_{5}, \mathrm{R}_{1}=-\mathrm{C}_{2} \mathrm{H}_{5}, \mathrm{R}_{2}=-\mathrm{OCH}_{3}, \mathrm{R}_{3}=\mathrm{R}_{4}=\mathrm{H}$

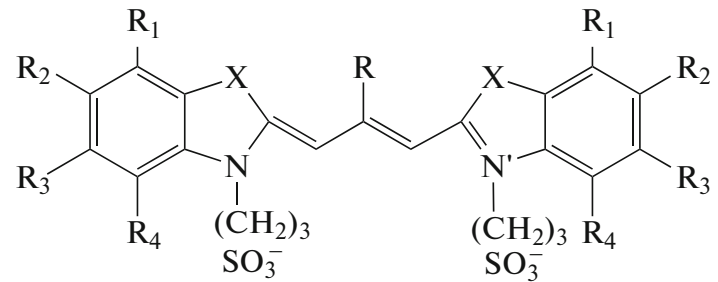

$2.1 X=S, \quad R=-\mathrm{CH}_{3}, \quad \mathrm{R}_{1}=\mathrm{R}_{2}=\mathrm{R}_{3}=\mathrm{R}_{4}=\mathrm{H}$

$2.2 \mathrm{X}=\mathrm{S}, \mathrm{R}=-\mathrm{CH}_{3}, \quad \mathrm{R}_{1}=\mathrm{R}_{2}=\mathrm{R}_{4}=\mathrm{H}, \mathrm{R}_{3}=-\mathrm{OCH}_{3}$

$2.3 \mathrm{X}=\mathrm{S}, \mathrm{R}=-\mathrm{CH}_{3}, \quad \mathrm{R}_{1}=\mathrm{R}_{2}=\mathrm{R}_{4}=\mathrm{H}, \quad \mathrm{R}_{3}=-\mathrm{Cl}$

$2.4 X=S, \quad R=-C_{3}, \quad R_{1}=R_{2}=R_{4}=H, \quad R_{3}=-C_{6} H_{5}$

$2.5 X=S, \quad R=-C_{2} H_{5}, \quad R_{1}=R_{3}=R_{4}=H, \quad R_{2}=-O_{3}$

2.6 $X=S, \quad R=-\mathrm{C}_{2} \mathrm{H}_{5}, \quad \mathrm{R}_{1}=\mathrm{R}_{2}=\mathrm{H}, \quad \mathrm{R}_{3,4}=-\mathrm{C}_{4} \mathrm{H}_{4}-$

$2.7 X=S, \quad R=-\mathrm{CH}_{3}, \quad \mathrm{R}_{1}=\mathrm{R}_{2}=\mathrm{H}, \quad \mathrm{R}_{3,4}=-\mathrm{C}_{4} \mathrm{H}_{4}-$

$2.8 X=S, \quad R=-\mathrm{CH}_{3}, \mathrm{R}_{1,2}=-\mathrm{C}_{4} \mathrm{H}_{4}, \quad \mathrm{R}_{3}=\mathrm{R}_{4}=\mathrm{H}$

$2.9 \mathrm{X}=\mathrm{S}, \quad \mathrm{R}=-\mathrm{C}_{2} \mathrm{H}_{5}, \quad \mathrm{R}_{1}=\mathrm{R}_{4}=\mathrm{H}, \quad \mathrm{R}_{2,3}=-\mathrm{OCH}_{2} \mathrm{O}-$

$2.10 X=O, R=-\mathrm{CH}_{3}, \quad \mathrm{R}_{1}=\mathrm{R}_{2}=\mathrm{R}_{4}=\mathrm{H}$

$2.11 X=O, R=-C_{3}, \quad R_{1}=R_{2}=R_{4}=H, \quad R_{3}=-C_{3}$

$2.12 \mathrm{X}=\mathrm{O}, \mathrm{R}=-\mathrm{CH}_{3}, \quad \mathrm{R}_{1}=\mathrm{R}_{2}=\mathrm{R}_{4}=\mathrm{H}, \mathrm{R}_{3}=-\mathrm{OCH}_{3}$

$2.13 X=O, \quad R=-C_{2} H_{5}, \quad R_{1}=R_{2}=R_{4}=H, \quad R_{3}=-C_{6} H_{5}$

$2.14 X=O, \quad R=-\mathrm{CH}_{3}, \quad \mathrm{R}_{1}=\mathrm{R}_{2}=\mathrm{H}, \quad \mathrm{R}_{3,4}=-\mathrm{C}_{4} \mathrm{H}_{4}-$

$2.15 X=\mathrm{O}, \mathrm{R}=-\mathrm{CH}_{3}, \mathrm{R}_{1,2}=-\mathrm{C}_{4} \mathrm{H}_{4}, \quad \mathrm{R}_{3}=\mathrm{R}_{4}=\mathrm{H}$

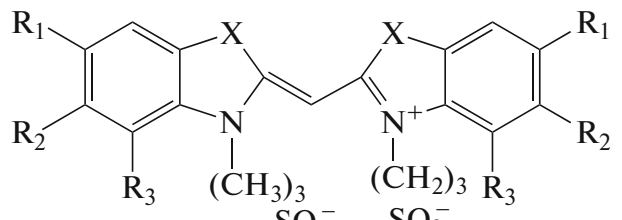

$\mathrm{SO}_{3}^{-} \quad \mathrm{SO}_{3}^{-}$

$1.1 X=S, R_{1}=R_{2}=R_{3}=H$

$1.2 X=S, R_{1}=H, R_{2,3}=-\mathrm{C}_{4} \mathrm{H}_{4}-$

$1.3 \mathrm{X}=\mathrm{S}, \mathrm{R}_{1}=\mathrm{R}_{3}=\mathrm{H}, \mathrm{R}_{2}=-\mathrm{OCH}_{3}$

$1.4 \mathrm{X}=\mathrm{S}, \mathrm{R}_{1,3}=-\mathrm{OCH}_{2} \mathrm{O}-, \mathrm{R}_{2}=\mathrm{H}$

$1.5 X=\mathrm{O}, \mathrm{R}_{1}=\mathrm{R}_{2}=\mathrm{R}_{3}=\mathrm{H}$

1.6 $X=O, R_{1}=-\mathrm{OCH}_{3}, \mathrm{R}_{2}=\mathrm{R}_{3}=\mathrm{H}$<smiles>[R]c1c([R])c([R])c2c(c1[R])c([X])c(CCC)n2[R]</smiles>

$n=2 \mathrm{R}=-\left(\mathrm{CH}_{2}\right)_{3} \mathrm{SO}_{3}^{-}$

$3.1 X=S, \quad R_{1}=R_{2}=R_{3}=R_{4}=H$

3.2 $\mathrm{X}=\mathrm{S}, \mathrm{R}_{1}=\mathrm{R}_{2}=\mathrm{H}, \mathrm{R}_{2,3}=-\mathrm{C}_{4} \mathrm{H}_{4}-$

3.3 X $=\mathrm{S}, \quad \mathrm{R}_{1}=\mathrm{R}_{2}=\mathrm{R}_{4}=\mathrm{H}, \quad \mathrm{R}_{3}=-\mathrm{OCH}_{3}$

$3.4 X=S, \quad R_{1}=\mathrm{R}_{4}=\mathrm{H}, \mathrm{R}_{2,3}=-\mathrm{OCH}_{2} \mathrm{O}-$

3.5 $\mathrm{X}=\mathrm{O}, \mathrm{R}_{1}=\mathrm{R}_{2}=\mathrm{R}_{4}=\mathrm{H}, \mathrm{R}_{3}=-\mathrm{OCH}_{3}$

3.6 $\mathrm{X}=\mathrm{O}, \mathrm{R}_{1}=\mathrm{R}_{2}=\mathrm{R}_{3}=\mathrm{R}_{4}=\mathrm{H}$

$n=3 \mathrm{R}=-\left(\mathrm{CH}_{2}\right)_{4} \mathrm{SO}_{3}^{-}$

$4.1 \mathrm{X}=-\mathrm{C}\left(\mathrm{CH}_{3}\right)_{2}-, \mathrm{R}_{1,2}=-\mathrm{C}_{4} \mathrm{H}_{4}-, \mathrm{R}_{3}=\mathrm{R}_{4}=\mathrm{H}$

$4.2 X=S, \quad R_{1,2}=-\mathrm{C}_{4} \mathrm{H}_{4}-, \quad \mathrm{R}_{3}=\mathrm{R}_{4}=\mathrm{H}$

$4.3 \mathrm{X}=\mathrm{S}, \mathrm{R}_{1}=\mathrm{R}_{2}=\mathrm{H}, \mathrm{R}_{3,4}=-\mathrm{C}_{4} \mathrm{H}_{4}-$

$4.4 X=S, R_{1}=R_{2}=R_{4}=H, R_{3}=-O_{3}$

4.5 $X=S, \quad R_{1}=R_{2}=R_{3}=R_{4}=H$

4.6 $\mathrm{X}=\mathrm{O}, \mathrm{R}_{1}=\mathrm{R}_{4}=\mathrm{H}, \mathrm{R}_{2,3}=-\mathrm{OCH}_{2} \mathrm{O}-$

$4.7 \mathrm{X}=\mathrm{O}, \mathrm{R}_{1,2}=-\mathrm{C}_{4} \mathrm{H}_{4}-, \mathrm{R}_{3}=\mathrm{R}_{4}=\mathrm{H}$

$4.8 \mathrm{X}=\mathrm{O}, \mathrm{R}_{1}=\mathrm{R}_{2}=\mathrm{H}, \quad \mathrm{R}_{3,4}=-\mathrm{C}_{4} \mathrm{H}_{4}-$

$4.9 X=O, R_{1}=R_{2}=R_{4}=H, R_{3}=-\mathrm{OCH}_{3}$

4.10 $X=O, R_{1}=R_{2}=R_{3}=R_{4}=H$

Fig. 1. Structural formulas of cationic and anionic mono-, tri-, penta-, and heptamethine cyanine dyes. 
<smiles>[R]C1=C([R])C(=C2C(=O)C(c3c([R])c([R])c(O)c([R])c3[R])=C2O)C([R])=C([R])C1=O</smiles>

SD1 $\mathrm{R}_{1}=\mathrm{R}_{2}=\mathrm{H}$

SD2 $\mathrm{R}_{1}=\mathrm{H}, \mathrm{R}_{2}=-\mathrm{I}$

SD3 $\mathrm{R}_{1}=-\mathrm{OH}, \mathrm{R}_{2}=-\mathrm{I}$

SD4 $\mathrm{R}_{1}=-\mathrm{OH}, \mathrm{R}_{2}=\mathrm{H}$

SD5 $\mathrm{R}_{1}=\mathrm{H}, \mathrm{R}_{2}=-\mathrm{Br}$

SD6 $\mathrm{R}_{1}=-\mathrm{OH}, \mathrm{R}_{2}=-\mathrm{Br}$

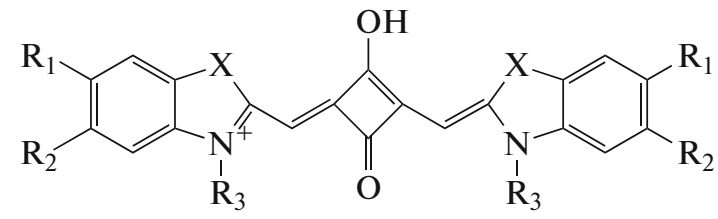

SD1.1 $\mathrm{X}=-\mathrm{C}\left(\mathrm{CH}_{3}\right)_{2}-, \mathrm{R}_{1}=-\mathrm{SO}_{3}^{-}, \mathrm{R}_{2}=\mathrm{H}, \mathrm{R}_{3}=-\mathrm{C}_{2} \mathrm{H}_{5}$

SD1.2 $\mathrm{X}=-\mathrm{C}\left(\mathrm{CH}_{3}\right)_{2}-, \mathrm{R}_{1}=\mathrm{R}_{2}=\mathrm{H}, \mathrm{R}_{3}=-\mathrm{C}\left(\mathrm{CH}_{2}\right)_{3} \mathrm{SO}_{3}^{-}$

SD1.3 $X=S, R_{1}=\mathrm{R}_{2}=\mathrm{H}, \mathrm{R}_{3}=-\left(\mathrm{CH}_{2}\right)_{3} \mathrm{SO}_{3}^{-}$

SD1.4 $X=S, R_{1}=-\mathrm{OCH}_{3}, \mathrm{R}_{2}=\mathrm{H}, \mathrm{R}_{3}=-\left(\mathrm{CH}_{2}\right)_{3} \mathrm{SO}_{3}^{-}$

SD1.5 $X=S, R_{1}=-\mathrm{CH}_{3}, \mathrm{R}_{2}=\mathrm{H}, \mathrm{R}_{3}=-\left(\mathrm{CH}_{2}\right)_{3} \mathrm{SO}_{3}^{-}$

SD1.6 $X=S, R_{1}=R_{2}=-C l, R_{3}=-\left(\mathrm{CH}_{2}\right)_{3} \mathrm{SO}_{3}^{-}$

SD1.7 $\mathrm{X}=\mathrm{S}, \mathrm{R}_{1}=-\mathrm{SO}_{3}^{-}, \mathrm{R}_{2}=\mathrm{H}, \mathrm{R}_{3}=-\mathrm{C}_{2} \mathrm{H}_{5}$

Fig. 2. Structural formulas of squarylium dyes.

(a)

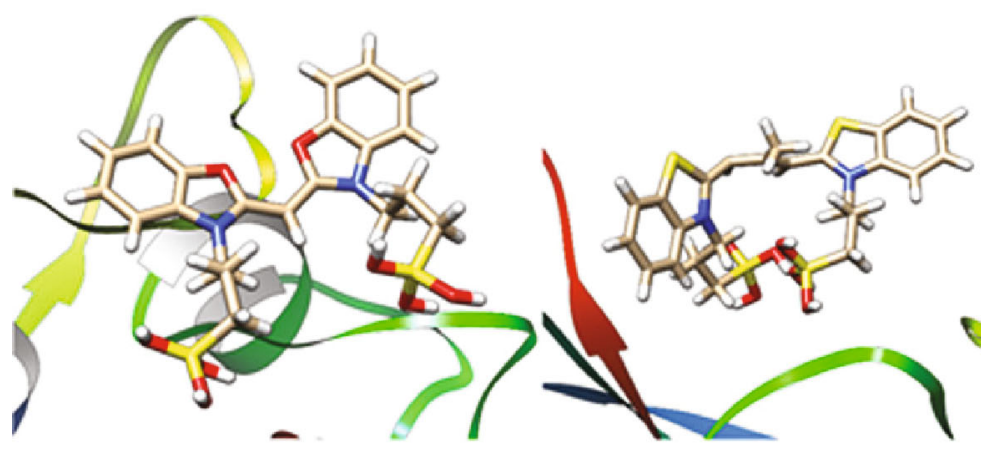

(b)

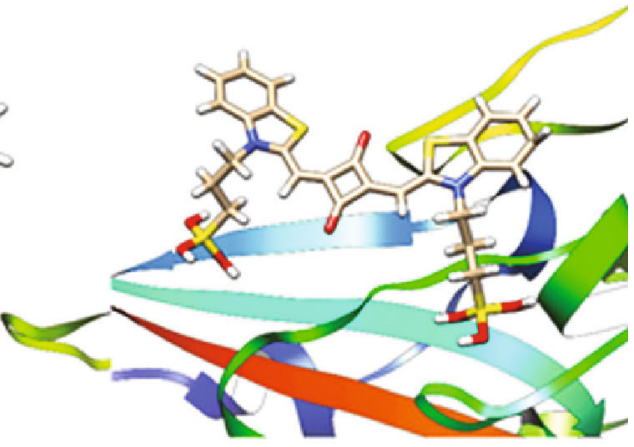

Fig. 3. Spatial docking of dyes with S (PDB ID 7BZ5 structure): (a) oxa-monomethine cyanine 1.5, (b) thiacarbocyanine 2.1, and (c) squarylium dye SD1.3.

The configurations of thia-dyes 3.1-3.4 in the protein-bound state correspond to distorted trans-isomers and twisted periplanar configurations. The simulation data indicate that oxa-dyes 3.5 and 3.6 possess more planar trans-configurations.

Heptamethine cyanins. The docking of anionic thiheptamethine cyanines 4.2-4.6 and oxaheptamethine cyanines 4.7-4.10 (tricarbocyanines) with $S$ showed that the dyes without substituents in the terminal heterocyclic moieties of $\mathbf{4 . 5}$ and $\mathbf{4 . 1 0}$ have negative $E_{\text {tot }}$ values (Table 2). The introduction of methoxyl substituents into the terminal groups (dyes $\mathbf{4 . 4}$ and 4.9) further decreases the $E_{\text {tot }}$ value of thiacyanine and has an insignificant effect on the $E_{\text {tot }}$ of the oxa-dye. At the same time, the introduction of additional condensed benzene rings into the heterocyclic fragments sharply increases the $E_{\text {tot }}$ value to positive values for dyes 4.2, 4.3, and 4.8. A positive $E_{\text {tot }}$ value was also observed for indocyanine 4.1 bearing condensed benzene rings (indocyanine green) (Table 2). The heptamethine cyanine molecules in the complex with $\mathrm{S}$ are located at a distance of 6 to $13 \AA$ from the Pro93, AS94, Phe131, and Glu183 residues; the configurations of the dye molecules correspond mainly to trans-isomers.

\section{Docking of Squarylium Dyes}

Together with the classical polymethine dyes, the interaction of their related compounds, the squarylium dyes, with $\mathrm{S}$ was studied. Complexes of $\mathrm{S}$ with 13 squarylium dyes having different structures and molecular charges (neutral SD1-SD6 and anionic SD1.1-SD1.7 with sulfonate groups, Fig. 2) were simulated with molecular docking. The cis-isomers served as the starting structures for the SD1.1-SD1.7 dyes. Positive $E_{\text {tot }}$ values were observed for all neutral compounds SD1-SD6. Indeed, the $E_{\text {tot }}$ values for SD3, which has $\mathrm{OH}$ groups in the terminal rings, are $45.7 \pm 1.69 \mathrm{kcal} \mathrm{mol}^{-1}$, whereas the $E_{\text {tot }}$ value is lower by a factor of (almost) $11\left(4.1 \pm 0.36 \mathrm{kcal} \mathrm{mol}^{-1}\right)$ for 
Table 1. Molecular docking data of anionic mono- and trimethine cyanine dyes with S: total interaction energy $E_{\text {tot }}\left(\mathrm{kcal}^{\mathrm{mol}}{ }^{-1}\right)$, Van der Waals interaction energy $E_{\mathrm{vdW}}$, and electrostatic energy $E_{\mathrm{el}}$

\begin{tabular}{|c|c|c|c|c|}
\hline Dye & $\mathrm{X}$ & $E_{\text {tot }}$ & $E_{\mathrm{vdW}}$ & $E_{\mathrm{el}}$ \\
\hline \multicolumn{5}{|c|}{ Monomethine cyanines } \\
\hline 1.1 & \multirow{4}{*}{$\begin{array}{c}\mathrm{S} \\
\text { (thia-) }\end{array}$} & $-41.5 \pm 2.5$ & $-8.2 \pm 2.3$ & $-38.6 \pm 5.7$ \\
\hline 1.2 & & $-13.1 \pm 0.7$ & $-11.8 \pm 6.6$ & $-33.1 \pm 6.2$ \\
\hline 1.3 & & $-29.3 \pm 0.9$ & $-10.0 \pm 6.0$ & $35.0 \pm 5.3$ \\
\hline 1.4 & & $35.8 \pm 1.4$ & $-12.5 \pm 3.0$ & $-33.2 \pm 3.1$ \\
\hline 1.5 & \multirow{2}{*}{$\begin{array}{c}\mathrm{O} \\
(\mathrm{oxa}-)\end{array}$} & $-58.6 \pm 3.2$ & $-11.7 \pm 5.8$ & $-34.4 \pm 7.6$ \\
\hline 1.6 & & $-52.3 \pm 2.8$ & $-12.5 \pm 5.7$ & $-35.5 \pm 5.4$ \\
\hline \multicolumn{5}{|c|}{ Trimethine cyanines } \\
\hline 2.1 & \multirow{9}{*}{$\begin{array}{c}\mathrm{S} \\
\text { (thia-) }\end{array}$} & $-13.7 \pm 1.6$ & $-5.9 \pm 4.8$ & $-38.6 \pm 5.9$ \\
\hline 2.2 & & $-24.2 \pm 0.95$ & $-18.5 \pm 1.2$ & $-32.4 \pm 1.5$ \\
\hline 2.3 & & $-19.1 \pm 1.6$ & $-5.2 \pm 1.2$ & $-41.7 \pm 4.1$ \\
\hline 2.4 & & $18.8 \pm 0.47$ & $-14.9 \pm 6.2$ & $-41.9 \pm 9.1$ \\
\hline 2.5 & & $0.38 \pm 1.02$ & $-6.89 \pm 4.2$ & $-41.4 \pm 5.0$ \\
\hline 2.6 & & $7.06 \pm 2.8$ & $-16.5 \pm 6.7$ & $-30.2 \pm 8.0$ \\
\hline 2.7 & & $48.3 \pm 1.3$ & $-12.7 \pm 8.1$ & $-37.1 \pm 5.0$ \\
\hline 2.8 & & $84.5 \pm 1.0$ & $-18.0 \pm 4.7$ & $-31.6 \pm 5.0$ \\
\hline 2.9 & & $-18.2 \pm 0.97$ & $-10.2 \pm 7.0$ & $-38.0 \pm 6.2$ \\
\hline 2.10 & \multirow{6}{*}{$\begin{array}{c}\mathrm{O} \\
(\text { oxa-) }\end{array}$} & $-32.4 \pm 0.46$ & $-10.4 \pm 7.9$ & $-33.6 \pm 8.7$ \\
\hline 2.11 & & $-30.0 \pm 0.50$ & $-10.6 \pm 6.3$ & $-37.3 \pm 6.4$ \\
\hline 2.12 & & $63.5 \pm 2.1$ & $-6.9 \pm 5.1$ & $-40.6 \pm 5.7$ \\
\hline 2.13 & & $-1.05 \pm 0.78$ & $-17.6 \pm 2.7$ & $-34.9 \pm 5.0$ \\
\hline 2.14 & & $51.9 \pm 0.71$ & $-11.6 \pm 3.7$ & $-35.4 \pm 4.13$ \\
\hline 2.15 & & $-9.5 \pm 1.3$ & $-15.8 \pm 4.8$ & $-32.3 \pm 7.2$ \\
\hline
\end{tabular}

the SD1 dye, which has no such substituents. The high positive $E_{\text {tot }}$ values indicate that such dye complexes with $\mathrm{S}$ are unstable.

Low $E_{\text {tot }}$ values (Table 2) were obtained for the thia-dyes SD1.3 and SD1.7 after the docking of S complexes with squarylium dyes bearing indole and benzthiazole hetero groups SD1.1-SD1.7 (Fig. 2) and having a negative charge due to two sulfonate groups. The structure of the SD1.3 dye in the complex corresponds to a planar conformation, whereas the SD1.7 dye is twisted and the terminal heterogroups are out-of-plane. The SD1.3 and SD1.7 dye molecules are located at a distance of 5 to $10 \AA$ from the Pro130, Pro93, Glu132, and Glu183 residues. The other squarylium dyes had positive $E_{\text {tot }}$ values. Figure $3 \mathrm{c}$ shows the spatial structure of the complex of SD1.3 dye with $\mathrm{S}$ obtained after docking.

\section{DISCUSSION}

The results obtained show that the total charge of a dye molecule has the primary effect on the stability of noncovalent dye-S complexes. The $E_{\text {tot }}$ value is positive for cationic dye molecules or neutral molecules in the case of squarylium dyes, which indicates that complexes with $S$ are unstable. At the same time, the negative $E_{\text {tot }}$ values, indicating the possible stability of the complexes, were typical only of the anionic dyes. All this indicates that Coulomb interactions play an important role in binding a dye to $\mathrm{S}$. In addition, the $E_{\text {el }}$ value for all the anionic dyes, which characterizes the Coulomb interactions, is negative and is more than $E_{\mathrm{vdW}}$ in absolute value, which characterizes the Van der Waals interactions in the complex (Tables 1, 2). This also indicates that Coulomb forces play the leading role in the formation of a complex. 
Table 2. Molecular docking data for anionic penta-, heptamethine cyanine, and squarylium dyes with S: total interaction energy $E_{\text {tot }}$, Van der Waals interaction energy $E_{\mathrm{vdW}}$, and electrostatic energy $E_{\mathrm{el}}\left(\mathrm{kcal} \mathrm{mol}^{-1}\right)$

\begin{tabular}{|c|c|c|c|c|}
\hline Dye & $\mathrm{X}$ & $E_{\text {tot }}$ & $E_{\mathrm{vdW}}$ & $E_{\mathrm{el}}$ \\
\hline \multicolumn{5}{|c|}{ Pentamethine cyanines } \\
\hline 3.1 & \multirow{4}{*}{$\begin{array}{c}\mathrm{S} \\
\text { (thia-) }\end{array}$} & $-30.8 \pm 2.0$ & $-10.5 \pm 5.6$ & $-39.8 \pm 7.0$ \\
\hline 3.2 & & $58.3 \pm 1.14$ & $-22.4 \pm 3.4$ & $-33.5 \pm 2.6$ \\
\hline 3.3 & & $-34.6 \pm 2.1$ & $-11.8 \pm 3.4$ & $-40.5 \pm 4.8$ \\
\hline 3.4 & & $-11.4 \pm 0.89$ & $-10.4 \pm 5.3$ & $-45.3 \pm 4.6$ \\
\hline 3.5 & \multirow{2}{*}{$\begin{array}{c}\mathrm{O} \\
(\mathrm{oxa}-)\end{array}$} & $-39.2 \pm 3.2$ & $-5.3 \pm 7.6$ & $-47.9 \pm 4.9$ \\
\hline 3.6 & & $-53.4 \pm 1.42$ & $-13.3 \pm 6.0$ & $-37.7 \pm 6.4$ \\
\hline \multicolumn{5}{|c|}{ Heptamethine cyanins } \\
\hline 4.1 & $\mathrm{C}\left(\mathrm{CH}_{3}\right)_{2}$ (indo-) & $15.9 \pm 0.77$ & $-20.6 \pm 5.9$ & $-35.7 \pm 5.3$ \\
\hline 4.2 & \multirow{5}{*}{$\begin{array}{c}\mathrm{S} \\
\text { (thia-) }\end{array}$} & $10.3 \pm 1.24$ & $-16.3 \pm 2.46$ & $-39.4 \pm 4.3$ \\
\hline 4.3 & & $60.7 \pm 2.6$ & $-17.3 \pm 6.7$ & $-41.0 \pm 8.5$ \\
\hline 4.4 & & $-45.0 \pm 2.0$ & $-18.7 \pm 3.8$ & $-30.1 \pm 6.1$ \\
\hline 4.5 & & $-21.7 \pm 1.1$ & $-16.0 \pm 5.8$ & $-36.3 \pm 6.4$ \\
\hline 4.6 & & $-20.0 \pm 0.72$ & $-10.9 \pm 9.0$ & $-45.2 \pm 11.9$ \\
\hline 4.7 & \multirow{4}{*}{$\begin{array}{c}\mathrm{O} \\
(\mathrm{oxa}-)\end{array}$} & $-12.7 \pm 3.3$ & $-17.2 \pm 3.7$ & $-35.4 \pm 6.0$ \\
\hline 4.8 & & $59.1 \pm 0.95$ & $-15.6 \pm 7.2$ & $-36.9 \pm 7.9$ \\
\hline 4.9 & & $-32.8 \pm 1.04$ & $-13.0 \pm 5.4$ & $-38.8 \pm 4.3$ \\
\hline 4.10 & & $-38.4 \pm 1.65$ & $-8.3 \pm 4.0$ & $-45.1 \pm 6.3$ \\
\hline \multicolumn{5}{|c|}{ Squarylium dyes } \\
\hline SD1.1 & \multirow{2}{*}{$\mathrm{C}\left(\mathrm{CH}_{3}\right)_{2}$} & $19.6 \pm 1.89$ & $-12.9 \pm 3.5$ & $-33.4 \pm 4.6$ \\
\hline SD1.2 & & $22.7 \pm 0.86$ & $-2.83 \pm 3.8$ & $-49.1 \pm 5.6$ \\
\hline SD1.3 & \multirow{5}{*}{$\mathrm{S}$} & $-63.0 \pm 3.7$ & $-7.84 \pm 5.1$ & $-50.5 \pm 7.9$ \\
\hline SD1.4 & & $39.2 \pm 6.7$ & $-2.18 \pm 2.1$ & $-54.8 \pm 4.9$ \\
\hline SD1.5 & & $39.2 \pm 2.6$ & $-0.91 \pm 5.6$ & $-57.9 \pm 4.8$ \\
\hline SD1.6 & & $3.31 \pm 1.73$ & $-13.87 \pm 5.8$ & $-45.1 \pm 9.0$ \\
\hline SD1.7 & & $-60.7 \pm 2.2$ & $-7.1 \pm 1.30$ & $-46.0 \pm 2.4$ \\
\hline
\end{tabular}

Some structural differences also influence the stability of the complexes with $\mathrm{S}$, together with the charge. In particular, the presence or absence of additional condensed benzene or dioxymethylene rings in the terminal heterocycles in a molecule plays an important role. It is clear that many dyes without such cycles $(1.1,1.5,2.1,2.10,3.1,3.6,4.5,4.10$, and SD1.3 dyes) have negative $E_{\text {tot }}$ values, which indicates that they are stable. At the same time, some condensed rings or bulky substituents (for example, $-\mathrm{C}_{6} \mathrm{H}_{5}$ ) often lead to the instability of the complexes, which is expressed in positive $E_{\text {tot }}$ values $(\mathbf{1 . 4}, \mathbf{2 . 4}, \mathbf{2 . 7}, \mathbf{2 . 8}$, 2.14, 3.2, 4.1-4.3, and 4.8 dyes). This is probably due to the lower compactness of the latter and higher steric hindrances in the formation of a complex than in the case of dyes without additional cycles. In addition, there are more negative $E_{\text {tot }}$ values for oxa-dyes compared to those of the corresponding thia- and indoanalogs $(1.5-1.1,2.10-2.1,2.15-2.8,3.6-3.1,3.5-$ 3.3, 4.10-4.5, and 4.7-4.2 pairs of dyes, as well as 4.1, apart from pairs 2.12-2.2 and 4.9-4.4). This is also probably due to the more compact structure of oxa-dyes in comparison with that of the thia- and indo-analogs.

A substantially negative $E_{\text {tot }}$ value, which is a criterion of the stability of complexes with $\mathrm{S}$, indicates that the following dyes may be used as probes: monomethine cyanines $\mathbf{1 . 1}-\mathbf{1 . 3}, \mathbf{1 . 5}$, and 1.6; trimethine 
cyanine dyes 2.1-2.3, 2.9-2.11, and 2.15; pentamethine cyanines 3.1 and 3.3-3.6; heptamethine cyanines 4.4-4.7, 4.9, and 4.10; and squarylium dyes SD1.3 and SD1.7.

If the dyes are used as spectral-fluorescent probes, how sharply the spectral-fluorescent properties of dyes change during the complexation, together with the stability of the complexes, is an important parameter. Spectral shifts and an increase in fluorescence are typical of polymethine dyes during their noncovalent binding to biomacromolecules [2]. A significant sharp increase in the intensity of the fluorescence is observed for meso-substituted carbocyanines (trimethine cyanine dyes) due to the shift in the mobile cis-trans equilibrium, which makes it possible to detect very low concentrations of biomolecules, when they are used as fluorescent probes [20]. Thiacarbocyanines 2.2, 2.3, and 2.9, together with oxacarbocyanines 2.10 and 2.11, are extremely promising for further studies from this point of view.

It is important that dyes should absorb and fluoresce in the "transparency window" of the biological tissues (more than 600-650 nm [21, 22]). The dyes with a longer polymethine chain (pentamethine cyanines, heptamethine cyanines, and squarylium dyes) satisfy these conditions. Almost all pentamethine cyanines (except 3.2), heptamethine cyanines 4.4-4.7, 4.9, and 4.10, and squarylium dyes SD1.3 and SD1.7 are considered promising.

The photochemical properties of polymethine dyes can also be changed together with their spectral-fluorescent properties when they bind to the biomolecules. In particular, there is an increase in the quantum yield to the triplet state for trimethine cyanines [23, 24]. This property can further be used for photodynamic therapy - the damage to the target biomolecule under light (for example, a component of a virus, with which a dye binds, to inactivate the virus). Riboflavin together with UV light irradiation is currently used for the photochemical inactivation of the MERS-CoV and SARS-CoV-2 coronaviruses in blood serum [25, 26]. This study opens up the possibilities of using trimethine cyanine dyes, which form complexes with the biological components of viruses, for the same purpose. In this case, visible light, which penetrates deeper into the biological tissues than ultraviolet light, could be used. The trimethine cyanine dyes in the triplet state could initiate the damage to a biomolecule in such a complex.

\section{CONCLUSIONS}

The noncovalent interaction between various polymethine (cyanine and squarylium) dyes and the spike protein (S) of the SARS-CoV-2 coronavirus was studied by molecular docking. We showed that cationic or neutral dyes do not form stable complexes with this protein but some anionic dyes that could potentially form such complexes have been found. This made it possible to select dyes for further practical studies to develop spectral-fluorescent probes to detect SARS$\mathrm{CoV}-2$. We also showed that trimethine cyanine dyes may be used for photodynamic therapy to inactivate coronavirus.

\section{FUNDING}

This study was performed under the Russian Federation State Assignment no. 001201253314 (Institute of Biochemical Physics, Russian Academy of Sciences).

\section{REFERENCES}

1. H. A. Shindy, Dyes Pigm. 145, 505 (2017). https://doi.org/10.1016/j.dyepig.2017.06.029

2. A. S. Tatikolov, J. Photochem. Photobiol., C 13, 55 (2012). https://doi.org/10.1016/j.jphotochemrev.2011.11.001

3. A. S. Tatikolov, P. G. Pronkin, L. A. Shvedova, and I. G. Panova, Russ. J. Phys. Chem. B 13, 900 (2019). https://doi.org/10.1134/S0207401X19120185

4. D. Sivaraman, P. Biswas, L. N. Cella, M. V. Yates, and W. Chen, Trends Biotechnol. 29, 307 (2011). https://doi.org/10.1016/j.tibtech.2011.02.006

5. K. Vus, U. Tarabara, Z. Balklava, et al., J. Mol. Liq. 302, 112569 (2020). https://doi.org/10.1016/j.molliq.2020.112569

6. M. A. Beg and F. Athar, Pharm. Pharmacol. Int. J. 8, $163(2020)$. https://doi.org/10.15406/ppij.2020.08.00292

7. E. Tazikeh-Lemeski, S. Moradi, R. Raoufi, et al., J. Biomol. Struct. Dyn., 0739 (2020). https://doi.org/10.15406/ppij.2020.08.00292

8. N. A. Al-Masoudi, R. S. Elias, and B. Saeed, Biointerface Res. Appl. Chem. 10, 6444 (2020). https://doi.org/10.33263/BRIAC105.64446459

9. C. S. de Magalhães, H. J. C. Barbosa, and L. E. Dardenne, Genetic and Evolutionary Computation - GECCO 2004, Vol. 3102 of Lecture Notes in Computer Science (Springer, Berlin, Heidelberg, 2004). https://doi.org/10.1007/978-3-540-24854-5_382004

10. C. S. de Magalhaes, D. M. Almeida, H. J. C. Barbosa, and L. E. Dardenne, Inf. Sci. 289, 206 (2014). https://doi.org/0.1016/j.ins.2014.08.002

11. Y. Wu, F. Wang, C. Shen, et al., Science (Washington, DC, U. S.) 368 (6496), 1274 (2020).

https://doi.org/10.1126/science.abc2241

12. M. D. Hanwell, D. E. Curtis, D. C. Lonie, et al., J. Cheminformatics 4, 17 (2012). https://doi.org/10.1186/1758-2946-4-17

13. Avogadro: Open Source Molecule Building and Visualization Tool, Vers. 1.2.0. http://avogadro.cc. Accessed August 11, 2020.

14. Z. Yang, K. Lasker, D. Schneidman-Duhovny, et al., J. Struct. Biol. 179, 269 (2012). https://doi.org/10.1016/j.jsb.2011.09.006

15. UCSF Chimera: Visualization System for Exploratory Research and Analysis, Vers. 1.13.1. http://www.rbvi. ucsf.edu/chimera. Accessed August 11, 2020. 
16. A. S. Tatikolov, T. M. Akimkin, A. S. Kashin, and I. G. Panova, High Energy Chem. 44, 224 (2010).

17. A. M. Kolesnikov and F. A. Mikhailenko, Russ. Chem. Rev. 56, 275 (1987).

18. T. M. Akimkin, A. S. Tatikolov, and S. M. Yarmolyuk, High Energy Chem. 45, 222 (2011).

19. V. Khimenko, A. K. Chibisov, and H. Görner, J. Phys. Chem. A 101, 7304 (1997).

https://doi.org/10.1021/jp971472b

20. P. G. Pronkin, L. A. Shvedova, and A. S. Tatikolov, Biophys. Chem. 261, 106378 (2020). https://doi.org/10.1016/j.bpc.2020.106378

21. I. V. Krasnikov, V. E. Privalov, A. Yu. Seteikin, and A. E. Fotiadi, Vestn. SPbGU, Ser. 11., No. 4, 202 (2013).
22. M. S. Patterson, B. C. Wilson, and D. R. Wyman, Lasers Med. Sci. 6, 379 (1991). https://doi.org/10.1007/bf02042460

23. P. G. Pronkin, A. S. Tatikolov, V. I. Sklyarenko, and V. A. Kuz'min, High Energy Chem. 40, 252 (2006).

24. P. G. Pronkin, A. S. Tatikolov, V. I. Sklyarenko, and V. A. Kuz'min, High Energy Chem. 40, 403 (2006).

25. S. D. Keil, R. Bowen, and S. Marschner, Transfusion 56, 2948 (2016). https://doi.org/10.1111/trf.13860

26. S. D. Keil, I. Ragan, S. Yonemura, et al., Vox Sang 115, 495 (2020).

https://doi.org/10.1111/vox.12937

Translated by A. Tulyabaev 